\title{
POLO DE CONFECÇÕES DO AGRESTE DE PERNAMBUCO: FORMAÇÃO DE AGLOMERADO PRODUTIVO E SUAS DINÂMICAS ESPACIAIS
}

Twane Maria Cordeiro Xavier

Universidade Federal de Pernambuco, Centro de Filosofia e Ciências Humanas Pós-Graduação em Geografia, Recife, PE, Brasil twane.xavier@gmail.com

\begin{abstract}
RESUMO
Entender as relações entre a especialização nas atividades econômicas de uma região produtiva e sua configuração enquanto polo, partindo de uma compreensão das relações entre os municípios, foi o objetivo geral deste trabalho. Com base em dados relacionados ao quantitativo de produção voltada para confecção, deslocamento pendular para trabalho e deslocamento para vendas, foram identificadas as cidades que compõem o Polo de Confecções do Agreste de Pernambuco, tendo em conta as diferentes intensidades dessas atividades entre uma área central e uma área periférica na região produtiva. Com isso, o resultado apresentado foi a compreensão da configuração regional composta pelos municípios que mais se destacaram em relação aos dados observados e a formação das áreas de abrangência da região produtora em dois níveis de intensidade.
\end{abstract}

Palavras-chave: Atividade de confecção. Arranjo Produtivo Local. Regionalização.

\section{CLOTHING POLE OF PERNAMBUCO: FORMATION OF PRODUCTIVE CLUSTER AND ITS SPATIAL DYNAMICS}

\begin{abstract}
To comprehend the relationships between specialization in economic activities of a productive region and its configuration as a pole, starting from the understanding of municipalities relationships, was the objective of this work. Based on data related to the quantity of production destined for confection, commuting migration to work and sales, we sought to identify the cities of the Clothing Pole of Pernambuco, taking into account the different intensities of these activities between a core and a peripheral area in the productive region. It was possible to identify the regional configuration composed by the municipalities that stood out the most in relation to the data observed and the areas of coverage of the producing region were presented in two levels of intensity.
\end{abstract}

Keywords: Clothing activities. Cluster. Regionalism.

\section{INTRODUÇÃO}

O trabalho com confecções no agreste do estado de Pernambuco teve sua origem em meados do século 20, por meio de produção de roupas em pequena escala para serem vendidas nas feiras das próprias cidades, com fabricação artesanal iniciada principalmente em Santa Cruz do Capibaribe (LIRA, 2006). Nos anos seguintes, deu-se início à comercialização através de feira, denominada Feira da Sulanca (DIEESE, 2010). A produção era especializada em confeccionar roupas de baixo custo, principalmente com retalhos vindos do Sudeste do país, e foi rapidamente absorvida como meio de trabalho também nos municípios vizinhos: Caruaru e Toritama, nos anos 1970 e 1980, respectivamente (DIEESE, 2010; VÉRAS DE OLIVEIRA, 2011; PEREIRA NETO, 2013), e elas se tornaram as três principais cidades do polo. As roupas eram vendidas nas chamadas Feiras da Sulanca.

Aos poucos, a dinâmica provocada pelas atividades de confecções nessas cidades atingiu outros municípios limítrofes, fazendo com que não só as três principais cidades, mas a região do agreste central e setentrional, que dependia mais especificamente da agricultura e da pecuária, tivesse sua realidade adaptada às novas possibilidades acrescidas pela indústria de confecções (LIRA, 2006). Com o tempo, a produção cresceu e ganhou destaque a nível estadual e, posteriormente, nacional. A região transformouse em polo atrativo para pequenos investidores, comerciantes e trabalhadores, proporcionando crescimento econômico para o agreste pernambucano. Isso ocorreu porque, na medida em que uma cidade ou um conjunto de cidades concentra alguma atividade específica, há um ganho de destaque para a localidade e o aumento da oferta de emprego torna-se um atrativo para pessoas de municípios vizinhos

$\begin{array}{llllll}\text { Caminhos de Geografia } \quad \text { Uberlândia - MG } & \text { v. 21, n. } 73 \quad \text { Mar/2020 } & \text { p. 429-444 Página } 429\end{array}$


e até mesmo das áreas rurais. A população do agreste do estado teve, a partir dos aglomerados de micro e pequenas indústrias que surgiram nas cidades com atividades de confecções, uma alternativa para 0 trabalho na agricultura (LIRA, 2006).

O estudo aqui desenvolvido pretende, como objetivo, entender as relações entre a especialização econômica da região e sua configuração enquanto polo, partindo de uma compreensão das relações entre os municípios. Assim, buscou-se identificar as cidades que compõem o Polo e sua relação com o as atividades contidas nele, tendo em conta as diferentes intensidades dessas atividades entre uma área "core" e uma área periférica no âmbito dessa região produtiva.

A transformação espacial que tem ocorrido nos municípios que compõem o Polo de Confecções do Agreste Pernambucano nos últimos anos é evidente, pois, por se tratar de uma região onde há uma especialização produtiva, as mudanças econômicas e sociais ocorridas, à exemplo das atividades de confecções tornando-se principal fonte de renda para a população, resultaram num dinamismo bastante intenso. Isso pode ser visto também por meio da consolidação dessas atividades na economia das cidades envolvidas, que passaram a investir no ramo, com objetivo de acompanhar a expansão do mercado, influenciando ainda mais na transformação dos municípios.

\section{CONTEXTO HISTÓRICO DO POLO DE CONFECÇÕES DO AGRESTE DE EPRNAMBUCO}

Apesar da confecção na região ter seu início mais direcionado à mercadoria de baixo custo, há atualmente maior diversificação e qualificação na produção, resultando na possibilidade de agregação de valor às peças desenvolvidas. Tendências da moda, diretrizes de mercado e maior alcance da rede de compradores, têm feito esse aglomerado tornar-se cada vez mais especializado.

A cidade de Caruaru passou a desenvolver atividades de confecção na década de 1970, mas diferente das outras duas cidades, ela possuía economia mais diversificada, pois já era constituída como importante dentro do estado, principalmente por estar numa localização estratégica entre a capital (Recife) e o sertão de Pernambuco. Nela existia uma feira de artigos populares e artesanais, antes mesmo da chegada da Sulanca. Apesar ter sido construído um complexo para alocação das lojas de confecções em 2004, denominado Polo Caruaru, a tradicional Feira da Sulanca não deixou de existir no centro, adquirindo uma grande proporção que trouxe consigo um crescimento se deu de modo espontâneo (LIRA, 2006; PEREIRA NETO, 2013).

Toritama só começou a desenvolver atividade produtiva e comercial de confecção a partir de 1980, com sua especialização voltada para as peças em jeans. Ela foi também a primeira cidade a implantar um centro comercial exclusivo para venda dos produtos têxteis, em 2001, que possui mais de 1000 estabelecimentos. Enquanto em Santa Cruz do Capibaribe, o centro específico para vendas só foi inaugurado em 2006, um parque com mais de 10 mil pontos comerciais que chega a atender cerca de 150 mil clientes por semana, sendo as segundas e as terças-feiras, os dias de maior movimento, e em períodos festivos, acrescenta-se o domingo. O Moda Center Santa Cruz, como é denominado, é considerado o maior shopping atacadista de confecções da América Latina (SEBRAE, 2013).

Com o crescimento das atividades de confecção, os municípios que fazem parte do polo de confecções do estado passaram por modificações nítidas. Mudanças estruturais na alocação das distribuidoras e do comércio trouxeram consigo nova configuração espacial para as cidades, como a construção dos centros de venda supracitados. Essas mudanças implicaram em transformações na cobertura do solo, na dinâmica econômica e na infraestrutura urbana das cidades. Alterações que, provavelmente, afetaram a população como um todo, mostrando não só os aspectos positivos desse crescimento, como também os negativos, refletindo em uma dinâmica que influenciou na decisão pela escolha da região para a realização desta pesquisa. De acordo com o SEBRAE (2013, p.14), "nos dez municípios onde se concentra a atividade confeccionista no agreste pernambucano, há mais de 100 mil pessoas ocupadas em produzir peças de vestuário. Muitas, em empregos formais; a maioria, ainda não".

A produção na região exerce um papel de destaque não apenas por possuir grande número de empresas relacionadas à atividade de confecção, tanto de empresas formais quanto das informais (fabricos), mas também por atrair grande fluxo de compradores semanalmente, com maio/junho e novembro/dezembro como os meses de maior movimentação. Os itens produzidos são variados e se adequam ao que dita o mercado da moda. A mão de obra é composta, majoritariamente, por pessoal com baixa escolaridade, "especialmente na principal etapa do processo produtivo, que é a costura, o que faz com que essa fase seja bastante dependente da habilidade, ritmo e qualidade tática dos trabalhadores envolvidos" (PEREIRA NETO, 2013, p. 163). 
O trabalho no ramo das confecções faz parte da realidade das famílias locais, pois a maior parcela de empreendimentos voltados para a produção consiste nos fabricos ou facções, onde boa parte da família participa do processo produtivo, desde as crianças até os mais velhos. Algumas crianças e adolescentes, influenciados por essa dinâmica, preferem fazer parte da produção e acabam deixando a escola em segundo plano ou abandonando-a, porque veem nesse trabalho o melhor caminho para o crescimento financeiro. São grandes jornadas de trabalho, muitas vezes realizadas em ambientes insalubres, sem folga semanal remunerada, visando o máximo de lucro (LIRA, 2006; VÉRAS DE OLIVEIRA, 2011), resultando numa precarização do trabalho e numa consequente exploração de mão de obra infantil.

A especialização teve um destaque tão eminente, que a partir dos anos 2002, algumas instituições em conjunto com o Sindicato das Indústrias do Vestuário do Estado de Pernambuco (SINDIVEST) e o Serviço Brasileiro de Apoio às Micro e Pequenas Empresas (SEBRAE), perceberam a oportunidade de aumentar a divulgação da região através da mudança do nome dado às feiras, e deixaram de usar "Feira da Sulanca", para utilizar "Polo de Confecções do Agreste de Pernambuco" ou "Polo da Moda de Pernambuco". Também nesse período, deu-se início a busca por desenvolver grandes projetos para o setor, como o "Projeto de Desenvolvimento do Polo de Confecções do Agreste", sob comando do SEBRAE, em parceria também com o Serviço Nacional de Aprendizagem Industrial (SENAI), o SINDVEST, o Governo do Estado e outras associações (VÉRAS DE OLIVEIRA, 2011; PEREIRA NETO, 2013). Cabe ressaltar que algumas cidades do agreste pernambucano têm se destacado com a atividade de confecções em termos de produção nacional e até internacional, gerando impacto econômico e social sobre a região, transformando o espaço urbano por meio da intensa atividade industrial e, consequentemente, comercial.

As cidades fazem parte de um processo cada vez mais complexo de interligações resultantes do sistema econômico predominante na atualidade, e possuem conexões tanto próximas quanto distantes, por meio das redes físicas e não físicas existentes. Muitas vezes elas possuem pouca dinâmica local, ou são apenas consideradas como nós que contribuem para a conectividade de uma grande rede urbana, ou as vezes possuem relações diretas com a demanda e a especialização da região onde se encontram; especialização esta, completamente ditada pelo consumo produtivo (SANTOS, 1994). Os espaços em pequenas cidades são, normalmente, compostos por população que possui a atividade agropecuária como principal fonte de renda. No entanto, isso não é uma afirmativa que deve ser generalizada, por isso, Fresca (2010, p.78) já apontava que "mudanças quantitativas e qualitativas vêm ocorrendo no terciário das pequenas cidades, suprindo, em parte, demandas de seu mercado consumidor, seja pela presença dos estabelecimentos físicos, bem como pelo comércio via internet". A força de trabalho local em algumas dessas cidades, também atua em setor industrial, chegando a trazer expressiva contribuição local e regional, que resulta em aumento de renda para a população e para o município (FRESCA, 2010). Elas, apesar de consideradas pequenas, interioranas e as vezes sem muita infraestrutura urbana, têm passado por mudanças que são resultantes das transformações que ocorrem devido às novas demandas espaciais.

A dinâmica da pequena cidade sofre influência direta das cidades maiores que se localizam mais próximas a ela, pois nela existe certo grau de dependência e lacunas em áreas econômicas, sociais e até mesmo educacionais, que outras cidades próximas podem suprir, mesmo que parcialmente. O polo de confecções aqui retratado, que é formado em sua maioria por uma rede de pequenas cidades, se torna um reflexo dessa influência e interdependência.

Cidades de menor porte, que antes eram vistas apenas como áreas de suporte para as grandes cidades, hoje têm adquirido importância do ponto de vista estratégico, principalmente no processo de valorização diferencial que visa o crescimento econômico local articulado com uma rede em escala mais abrangente (a nível regional, estadual ou internacional). Não apenas relações de hierarquia se fazem presentes, mas também as de heterarquia, no sentido proposto por Márcio Catelan em sua tese de doutoramento, que a apresenta como conjunto de interações espaciais interescalares na rede urbana. São relações que não acontecem apenas por meio de verticalidades, mas também através das horizontalidades, "cujas interações espaciais e territoriais se dão entre centros de mesmos níveis e entre centros de níveis diferentes" (CATELAN, 2013, p.80). Nesse aspecto, as cidades que fazem parte do polo de confecções aqui estudado, estabelecem, entre si, tanto as relações hierárquicas quanto as heterárquicas.

\section{UM AGLOMERADO PRODUTIVO COMO TRANSFORMADOR DO ESPAÇO URBANO}

O Polo de Confecções do Agreste de Pernambuco é considerado, pelo governo do estado, como um Arranjo Produtivo Local, o que contribui para a sua participação em programas e investimentos

$\begin{array}{llllll}\text { Caminhos de Geografia } & \text { Uberlândia - MG } & \text { v. 21, n. 73 } & \text { Mar/2020 } & \text { p. 429-444 } & \text { Página } 431\end{array}$


governamentais. No entanto, a discussão sobre essa nomenclatura por vezes pode parecer extensa (COSTA, 2010). Alguns estudos, por exemplo, divergem sobre o que pode ser considerado como APL ou aglomeração produtiva. Por isso, cabe aqui um esclarecimento sobre esses conceitos através de literatura já existente.

Na bibliografia voltada para estudos relacionados ao agrupamento de empresas, é possível identificar diversos nomes usados para classificá-las, tais como, centros industriais, clusters, complexo industrial, distritos industriais, sistemas produtivos locais, arranjos produtivos locais, polo de desenvolvimento industrial, aglomerações produtivas, dentre outros. Cada um deles possuindo características que por vezes podem ser muito próximas, e outras vezes não. Em se tratando de uma aglomeração de empresas voltadas para um determinado ramo, independente do nome que é dado ao fenômeno, ocorre transformação econômica na localidade, pois passa a existir um adensamento de atividades que permite a chegada de investimentos privados e públicos, de concorrência, de fluxo mais intenso de capital, de capacidade de inovação, bem como de mão-de-obra, atraída pela dinâmica econômica gerada pelo aglomerado. Contudo, nem sempre a transformação gerada atinge positivamente a população local.

Uma aglomeração produtiva, pode ser entendida como uma concentração de empresas de um dado setor no espaço, tendo em conta os seguintes aspectos ressaltados por CROCCO e outros, "à intensidade das trocas intra-aglomeração, à existência de relações de cooperação, o grau de especialização e desintegração vertical da aglomeração, o ambiente institucional voltado para dar suporte ao desenvolvimento da aglomeração, entre outros" (2006, p.213). Também considerada como relações interfirmas que possuem proximidade territorial, e que têm como principal característica o mesmo ramo ou ramo de relação direta das atividades econômicas existentes (RODRIGES, et al, 2012). Há, consequentemente, uma especialização produtiva do espaço ondem essas aglomerações se alocam, influenciando na transformação desse espaço.

Para falar sobre o conjunto de cidades abordado nesta pesquisa, cabe aqui, primeiramente, uma interpretação sobre os termos utilizados para caracterizar sua situação quanto à produção de confecções. Oficialmente, além do governo de Pernambuco, o Ministério do Desenvolvimento, Indústria e Comércio Exterior (MDIC) e o Instituto de Pesquisa Econômica Aplicada (IPEA), consideraram o Polo de Confecções do Agreste Pernambucano como uma unidade passível de ser classificada como Arranjo Produtivo Local (APL). Mas o que pode ser considerado como um APL?

Diversas são as interpretações sobre o que pode ser considerado como um APL na literatura brasileira, mas todas levam em conta a cooperação entre empresas como a base principal para a sua estruturação (SANTOS, et al, 2004). Marcos Rodrigues e outros autores (2012), entendem um APL como aglomerações formadas por agentes econômicos, políticos e sociais, que possuem interações entre eles, muitas vezes realizando atividades econômicas específicas em conjunto, que proporcionam aprendizado e cooperação, e podem resultar no crescimento da produção e da capacidade de inovação, por possuírem vínculos mais próximos e objetivos semelhantes. A relação próxima entre as micro e pequenas empresas, que são as mais encontradas em um APL, chega a proporcionar o sentido de comunidade, e pode envolver não apenas o contexto socioeconômico, mas também o político e cultural.

A nomeação de um aglomerado de empresas como um APL pode também estar associada a uma forma de gestão para aplicação de políticas públicas no local onde elas se concentram, ampliando as possibilidades para o desenvolvimento regional. Mas é a ação de um conjunto de agentes sociais produtores do espaço que possibilita o desenvolvimento do APL, pois como afirmam Simonetti e Kamimura (2017):

\begin{abstract}
Para que haja o crescimento e o desenvolvimento desses arranjos produtivos, é necessário existir uma sinergia do conhecimento, da regulação nas relações criadas pelos atores econômicos e sociais, amparados por sistemas institucionais voltados aos interesses e às necessidades das atividades desenvolvidas na região. Para que o projeto possua um sucesso competitivo, é necessária uma articulação entre as empresas e destas com o ambiente no qual estão inseridas, por meio de estruturas de apoio. (SIMONETTI e KAMIMURA, 2017, p.21)
\end{abstract}

A atuação do proprietário dos meios de produção, dos comerciantes, das associações, dos representantes governamentais e de agentes que fomentam o conhecimento, em conjunto, é que permite a construção e consolidação de um APL, ressaltando a importância da cooperação entre esses agentes. Os autores supracitados também acrescentam que "os APLs são mais propícios a desenvolverem-se em ambientes favoráveis à interação, à cooperação e à confiança entre os atores" (SIMONETTI e KAMIMURA, 2017, p.22).

$\begin{array}{llllll}\text { Caminhos de Geografia } & \text { Uberlândia - MG } & \text { v. 21, n. } 73 & \text { Mar/2020 } & \text { p. 429-444 } & \text { Página } 432\end{array}$


E é prendendo-se ao aspecto da cooperação que Costa (2010) ressalta que ela pode ser vista como a principal característica que diferencia a estruturação de um APL de uma aglomeração produtiva. $O$ fato de existirem laços de confiança e cooperação, contribuem para a formação de parcerias e aplicação de ações em conjunto, o que muitas vezes inexiste em aglomerados localizados nas regiões mais periféricas do país. A utilização dessa nomenclatura também passou a ser um sinônimo de modernidade e uma forma de chamar a atenção das agências de fomento, de planejamento e de pesquisa para esses locais, com intuito de influenciar no seu desenvolvimento (PICCININI, et al, 2011).

Além disso, em seu estudo sobre os APLs brasileiros, Costa (2010) ressalta que a possibilidade de encontrar, no país, um APL na concepção plena no termo é muito pequena, por isso prefere considerar grande parte desses arranjos apenas como aglomerados produtivos industriais com potencialidades de se tornarem APLs, principalmente nas regiões mais periféricas do Brasil: Norte, Nordeste e Centro-Oeste. Para ele, os aglomerados produtivos podem ser entendidos da seguinte maneira:

A maioria dos aglomerados apresenta uma conformação horizontal, composta por pequenos e microprodutores, sem a incidência de uma 'empresa ancora'. E, em geral, são extremamente relevantes para a economia local por gerarem boa parte dos empregos e da renda. Em que pese isto, com algumas exceções, o grau de informalidade das empresas é bastante significativo... com nível de qualificação baixo, e grande parte da mão de obra empregada em muitos aglomerados de caráter familiar, com boa parte não auferindo remuneração. (COSTA, 2010, p.153)

Aqui são expostas características que demonstram as diferenças entre uma aglomeração produtiva e um APL, a existência ou não de uma empresa que seja considerada como principal é uma delas. Além disso, a grande quantidade de informalidade na cadeia produtiva e de trabalhos realizados dentro das próprias famílias, é uma das mais discrepantes características encontradas em uma aglomeração. Em um APL existem aspectos relacionados à governança e estruturação política e econômica que uma aglomeração produtiva ainda não possui. E de acordo com essas interpretações, as características de aglomeração produtiva são as que mais se aproximam da região aqui estudada. Outras pesquisadoras como Sonia Lira (2009) e Maria Gilca Xavier (2006), também consideraram em seus estudos, o Polo de Confecções do Agreste de Pernambuco como um aglomerado produtivo, principalmente por possuir grande concentração de micro e pequenas empresas informais, pela dificuldade de os agentes produtivos agirem em conjunto ou cooperação, pela grande incidência de trabalho familiar e pela baixa qualificação profissional, como ressaltado nas características já expostas por Costa (2010). No caso da nomenclatura de "Polo de Confecções do Agreste de Pernambuco", instituída pelo SEBRAE, o uso do termo visa a divulgação do aglomerado de maneira comercial, retirando o foco do nome "Feira da Sulanca", e permite a caracterização mais formal das atividades desenvolvidas na região.

A ação dos agentes produtores de maneira articulada dentro da aglomeração produtiva é essencial para o seu desenvolvimento. A influência da aglomeração na região estudada é evidente quando se observa a transformação econômica das principais cidades que a compõem. Tendências da moda, diretrizes de mercado e maior alcance da rede de compradores, têm feito o polo tornar-se cada vez mais especializado, contribuindo até mesmo na elaboração de eventos de moda na região, a exemplo do Estilo Moda Pernambuco, que acontece em Santa Cruz do Capibaribe.

Uma das formas de identificar o crescimento econômico dos municípios a serem retratados aqui é por meio da observação da variação do Produto Interno Bruto (PIB) entre o final do século XX e a primeira década do século atual, pois o PIB corrente dos três principais municípios, por exemplo, cresceu entre 5 e 11 vezes no período de 1999 e 2010, de acordo com os dados do IBGE (2015). O Índice de Desenvolvimento Humano Municipal (IDHM), por sua vez, que na década de 1990 era inferior a 0,500 em todos os três principais municípios do polo, no ano de 2010 apresentou melhora significativa (Quadro 1).

Quadro 1 - PIB (x1000) e IDHM dos três principais municípios do Polo.

\begin{tabular}{|l|c|c|c|c|}
\hline MUNICÍPIOS & PIB 1999 & PIB 2010 & IDHM - 2000 & IDHM - 2010 \\
\hline Caruaru & $\mathrm{R} \$ 736.887,00$ & $\mathrm{R} \$ 3.872 .947,00$ & 0,558 & 0,677 \\
Sta. Cruz do Capibaribe & $\mathrm{R} \$ 114.228,00$ & $\mathrm{R} \$ 766.084,00$ & 0,520 & 0,648 \\
Toritama & $\mathrm{R} \$ 33.697,00$ & $\mathrm{R} \$ 387.474,00$ & 0,481 & 0,618 \\
\hline
\end{tabular}

Fonte - IBGE e PNUD (2018) 
Ao observar a evolução do índice subdividido em cada uma de suas dimensões fica claro que o crescimento não se deu apenas no âmbito econômico, mas abarcou também as áreas referentes a educação e a longevidade (Quadro 2). Essa relação pode estar ligada diretamente ao dinamismo econômico proporcionado pelo avanço das atividades de confecções, principalmente nos municípios historicamente menores, como Santa Cruz do Capibaribe e Toritama.

Quadro 2 - IDHM principais municípios do Polo subdividido nas três dimensões estudadas.

\begin{tabular}{|l|c|c|c|c|c|c|}
\hline \multirow{2}{*}{ MUNICÍPIOS } & \multicolumn{2}{c|}{ IDHM Renda } & \multicolumn{2}{c|}{ IDHM Longevidade } & \multicolumn{2}{c|}{ IDHM Educação } \\
\cline { 2 - 8 } & $\mathbf{2 0 0 0}$ & $\mathbf{2 0 1 0}$ & $\mathbf{2 0 0 0}$ & $\mathbf{2 0 1 0}$ & $\mathbf{2 0 0 0}$ & $\mathbf{2 0 1 0}$ \\
\hline Caruaru & 0,635 & 0,681 & 0,706 & 0,799 & 0,387 & 0,569 \\
Santa Cruz do Capibaribe & 0,633 & 0,667 & 0,734 & 0,806 & 0,302 & 0,506 \\
Toritama & 0,623 & 0,655 & 0,728 & 0,797 & 0,245 & 0,452 \\
\hline
\end{tabular}

A transformação ocorrida também é manifesta nos outros municípios que fazem parte dessa aglomeração produtiva, mas com menor intensidade. A delimitação do Polo de Confecções nessa pesquisa, foi realizada tendo em conta três diferentes bases de dados secundários. A primeira está baseada nos municípios de Pernambuco e da Paraíba que possuem consideráveis quantidades de empresas formais produtoras de confecções. A segunda, para demonstrar a centralidade e atração que o aglomerado produz, serão considerados os municípios de Pernambuco e da Paraíba que obtiveram quantidades consideráveis de deslocamento pendular para trabalho em direção a Santa Cruz do Capibaribe. E a terceira relacionada ao quantitativo de empreendedores, por município, que vendem seus produtos no Moda Center Santa Cruz. Santa Cruz do Capibaribe foi o município escolhido como foco dos deslocamentos aqui, por possuir o maior centro de comercial de confecções da região, e por possuir dados disponíveis relacionados à terceira variável citada acima. No entanto, não se pretende afirmar que ele é o município de maior importância econômica para a região, pois os outros dois municípios também apresentam relevância regional no que tange à produção e comercialização de materiais de vestuário.

\section{POLO DE CONFECÇÕES DO AGRESTE DE PERNAMBUCO: CIDADES PERTENCENTES E RELAÇÕES DE INFLUẾNCIA}

O Polo de Confecções do Agreste de Pernambuco não possui delimitação oficial, nem mesmo por meio da sua classificação enquanto Arranjo Produtivo Local pelo governo do Estado. As cidades principais são bastante conhecidas, devido à consolidação de seus comércios e indústrias voltadas para o ramo de confecções, mas as demais cidades não possuem tanto destaque assim, principalmente porque são, em sua maioria, um conjunto de pequenas cidades. Por isso, pretende-se aqui mostrar quais são as cidades que são atuantes no polo no que se refere à produção, e observar as que se relacionam mais intensamente com Santa Cruz do Capibaribe, tendo em conta a atividade comercial e o deslocamento pendular para trabalho. Neste trabalho foram utilizadas três variáveis para identificação das cidades pertencentes ao Polo. Esses dados serão expostos a seguir, acompanhados pela composição municipal da região produtora e das relações de influência existentes entre as cidades.

As cidades que fazem parte desse complexo voltado para a confecção, não se limitam apenas ao Agreste de Pernambuco, mas alcançam uma parcela de municípios localizados no Estado da Paraíba. Isso foi possível de ser identificado, por meio dos dados da Relação Anual de Informações Sociais (RAIS) e de um levantamento feito pela Secretaria de Desenvolvimento Econômico, Agricultura e Meio Ambiente da Prefeitura de Santa Cruz do Capiberibe, que captou a origem dos empreendedores que vendem no Moda Center Santa Cruz semanalmente.

Para a contagem dos estabelecimentos com atividade correlata à confecção, foram selecionadas as três categorias de divisão na CNAE 2.0: "Fabricação de produtos têxteis", "Confecção de artigos de vestuário e acessórios" e "Preparação de couro e fabricação de artefatos de couro, artigos para viagens e calçados", referente ao intervalo de 2006 a 2016 (período disponibilizado pela RAIS). Mesma seleção realizada pelo SEBRAE (2013), que nesse estudo, com auxílio da Datamétrica, apresentou uma estimativa dos empreendimentos informais, concluindo que "existiriam 4 (com a primeira decimal: 4,1) unidades

$\begin{array}{llllll}\text { Caminhos de Geografia } & \text { Uberlândia - MG } & \text { v. 21, n. } 73 & \text { Mar/2020 } & \text { p. 429-444 } & \text { Página } 434\end{array}$


produtivas informais para cada unidade produtiva formal" (SEBRAE, 2013, p.29). No entanto, diferente do SEBRAE, a busca pelos dados da RAIS não foi limitada aos 10 municípios por eles selecionados, e sim foi realizada uma busca ampla para Pernambuco e Paraíba, como citado anteriormente; bem como, não foram considerados os estabelecimentos que fizeram declaração de RAIS Negativa, na qual são fornecidos somente os dados cadastrais do estabelecimento relacionado ao CNPJ, quando a empresa não teve empregado ou manteve suas atividades paralisadas durante o ano-base.

Ainda sobre os dados da RAIS, a fim de especificar mais a área onde as atividades de confecção se concentram, foram selecionados os municípios que tinham ao menos cinco estabelecimentos produtivos no último ano de divulgação do dado (2016), e o quantitativo para cada município foi relacionado com o total de estabelecimentos voltados para a indústria da transformação, a fim de extrair o percentual de estabelecimentos relacionados à confecção. No quadro (Quadro 3) a seguir, encontram-se os municípios cujos valores foram superiores a $50 \%$.

Quadro 3 - Municípios com quantitativo de indústria da confecção com percentual superior a 50\% sobre o total de indústrias da transformação em PE e PB em 2016.

\begin{tabular}{|c|c|c|c|}
\hline UF - Município & $\begin{array}{c}\text { Total de Indústrias } \\
\text { da Confeç̧ão }\end{array}$ & $\begin{array}{c}\text { Total de Indústrias } \\
\text { da Transformação }\end{array}$ & $\begin{array}{c}\text { Percentual de Indústria } \\
\text { da Confeç̧ão sobre o } \\
\text { total da Transformação }\end{array}$ \\
\hline PE - Toritama & 333 & 353 & $94,33 \%$ \\
\hline PE - Santa Cruz do Capibaribe & 532 & 579 & $91,88 \%$ \\
\hline PE - Vertentes & 29 & 32 & $90,63 \%$ \\
\hline PE - Jataúba & 7 & 8 & $87,50 \%$ \\
\hline PE - Taquaritinga do Norte & 68 & 80 & $85,00 \%$ \\
\hline PE - Riacho das Almas & 38 & 45 & $84,44 \%$ \\
\hline PB - Itaporanga & 35 & 48 & $72,92 \%$ \\
\hline PE - Brejo da Madre de Deus & 29 & 40 & $72,50 \%$ \\
\hline PE - Cupira & 42 & 59 & $71,19 \%$ \\
\hline PE - Santa Maria do Cambucá & 8 & 12 & $66,67 \%$ \\
\hline PB - São Bento & 39 & 60 & $65,00 \%$ \\
\hline PE - Caruaru & 757 & 1235 & $61,30 \%$ \\
\hline PE - Surubim & 63 & 109 & $57,80 \%$ \\
\hline PE - São Caitano & 20 & 39 & $51,28 \%$ \\
\hline
\end{tabular}

A partir desse resultado, foi gerado um mapa com a disposição dos municípios que tiveram maiores percentuais de indústrias voltadas para a confecção (Figura 1). No mapa, é possível observar que a concentração de municípios com maior quantitativo se encontra na parte do agreste do Estado de Pernambuco, mais precisamente em sua área setentrional e central, abrangendo as cidades mais próximas das três principais do polo. Há um destaque maior para as cidades de Toritama, Santa Cruz do Capibaribe e Vertentes, cujo quantitativo de unidades voltadas para confecção ficou acima de $90 \%$, com 333, 532 e 29 unidades, respectivamente. Os municípios de Jataúba, Taquaritinga do Norte e Riacho das Almas, completam o grupo com valores acima de $80 \%$. No segundo grupo, com uma porcentagem entre $50 \%$ e $75 \%$, estão as cidades de Itaporanga e São Bento, na Paraíba, e Brejo da Madre de Deus, Cupira, Santa Maria do Cambucá, Caruaru, Surubim e São Caitano, em Pernambuco. As demais apresentaram quantitativo inferior a 50\%, mas não deixam de ser relevantes, principalmente as que se encontram mais próximas dos municípios com maiores quantitativos, ressaltando que esse número corresponde apenas unidades produtivas formais. 
Figura 1 - Mapa de municípios com unidades produtivas formais de confecção em PE e PB.

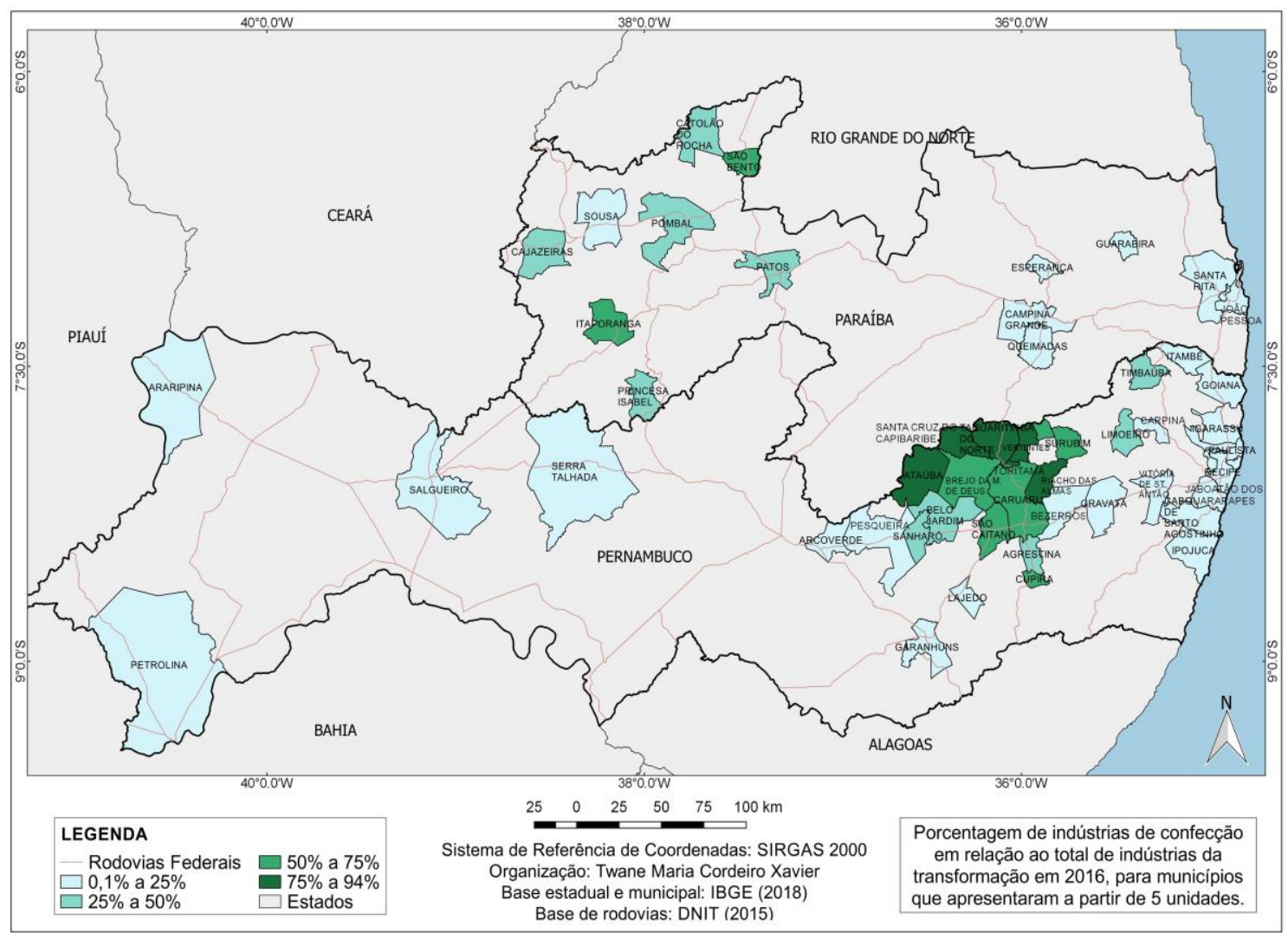

Fonte - Elaboração própria. (2018).

A cidade de Caruaru não está entre as que possuem maior percentual dessas unidades produtivas, porque sua economia é bem mais diversificada. Como cidade média e mais importante para o interior do Estado do ponto de vista estratégico, ela desponta como cidade com maior quantitativo de funções e oferta de serviços, inclusive classificada pelo IBGE como capital regional desde o REGIC de 2007, chegando a possuir, atualmente, uma grande quantidade de municípios influenciados por sua região imediata e intermediária (IBGE, 2017). A cidade de São Bento - PB (com 60\%), por sua vez, possui uma economia diferenciada das demais, pois é voltada para a produção de redes de dormir, e aparece como maior produtora do Brasil, alcançando a marca de 12 milhões de redes produzidas ao ano, vendidas para diversos países da América Latina, da Europa, da África e da Oceania (CARNEIRO, 2017). E em Itaporanga, no sertão paraibano, a especialidade é na produção de panos de prato, de chão e de toalhas, o que também difere do segmento mais desenvolvido no Agreste de Pernambuco, que é voltado para roupas/vestuário.

Com os dos dados da RAIS, também se observou a evolução da quantidade dessas unidades produtivas nos últimos 10 anos. Abaixo estão as cidades que tiveram um percentual de acima de $50 \%$ para o ano de 2016 (Quadro 4), conforme dado exposto no mapa anterior. São 14 cidades que se destacaram também na evolução dessa produção nos últimos anos, algumas delas saindo de apenas uma unidade produtiva, para 20 unidades, como São Caitano, que no ano de 2016 teve cerca de $51 \%$ de suas indústrias de transformação voltadas para atividades de confecção. A partir do ano de 2013 houve decréscimo no número de empresas formais, não significativo para resultar na queda da produção na região, pois existe uma parcela muito grande de empreendimentos de confecção informais na região. 
Quadro 4 - Unidades produtivas formais de confecção.

\begin{tabular}{|c|c|c|c|c|c|c|c|c|c|c|c|}
\hline Município & 2006 & 2007 & 2008 & 2009 & 2010 & 2011 & 2012 & 2013 & 2014 & 2015 & 2016 \\
\hline Itaporanga - PB & 11 & 11 & 12 & 16 & 28 & 26 & 31 & 34 & 33 & 34 & 35 \\
\hline São Bento - PB & 21 & 27 & 37 & 38 & 39 & 39 & 37 & 42 & 39 & 42 & 39 \\
\hline $\begin{array}{c}\text { Brejo da Madre de } \\
\text { Deus - PE }\end{array}$ & 5 & 5 & 7 & 11 & 16 & 24 & 28 & 31 & 28 & 31 & 29 \\
\hline Caruaru - PE & 603 & 657 & 691 & 695 & 738 & 768 & 781 & 800 & 812 & 799 & 757 \\
\hline Cupira - PE & 10 & 14 & 12 & 19 & 22 & 24 & 29 & 43 & 43 & 45 & 42 \\
\hline Jataúba - PE & 0 & 0 & 1 & 1 & 6 & 7 & 8 & 8 & 7 & 7 & 7 \\
\hline $\begin{array}{c}\text { Riacho das Almas } \\
\text { - PE }\end{array}$ & 16 & 21 & 23 & 25 & 32 & 42 & 35 & 42 & 49 & 42 & 38 \\
\hline $\begin{array}{l}\text { Santa Cruz Do } \\
\text { Capibaribe - PE }\end{array}$ & 266 & 301 & 315 & 352 & 423 & 452 & 482 & 523 & 551 & 550 & 532 \\
\hline $\begin{array}{l}\text { Santa Maria do } \\
\text { Cambucá - PE }\end{array}$ & 1 & 1 & 2 & 2 & 2 & 5 & 7 & 13 & 12 & 11 & 8 \\
\hline São Caitano - PE & 1 & 4 & 6 & 6 & 7 & 8 & 11 & 17 & 21 & 22 & 20 \\
\hline Surubim - PE & 19 & 25 & 26 & 40 & 47 & 53 & 58 & 52 & 63 & 64 & 63 \\
\hline $\begin{array}{l}\text { Taquaritinga do } \\
\text { Norte - PE }\end{array}$ & 24 & 31 & 30 & 33 & 50 & 54 & 58 & 62 & 64 & 67 & 68 \\
\hline Toritama - PE & 145 & 156 & 147 & 160 & 174 & 229 & 321 & 410 & 434 & 379 & 333 \\
\hline Vertentes - PE & 3 & 4 & 5 & 9 & 13 & 20 & 25 & 27 & 26 & 30 & 29 \\
\hline Total & 1125 & 1257 & 1314 & 1407 & 1597 & 1751 & 1911 & 2104 & 2182 & 2123 & 2000 \\
\hline
\end{tabular}

Com essa identificação, fica claro o destaque de algumas cidades em relação à produção. Mas um outro dado pode trazer mais detalhes sobre o conjunto de cidades que faz parte do Polo, que é o quantitativo, por município, de empreendedores que atuam no Moda Center Santa Cruz. Esse centro de comercialização conta com cerca de 10 mil locais de venda (9762 boxes e 727 lojas), com vendedores vindos de 54 municípios dos estados de Pernambuco e da Paraíba, de acordo com a Secretaria de Desenvolvimento, Agricultura e Meio Ambiente de Santa Cruz do Capibaribe (2013). A disposição desse dado está no mapa da próxima página (Figura 3).

Neste mapa, a grandeza da abrangência espacial que o centro de vendas exerce sobre a cidade é ressaltada. Semanalmente, empreendedores desses 54 municípios se deslocam para Santa Cruz do Capibaribe para vender suas mercadorias, sejam elas de produção própria ou revenda. A cidade fica cheia de consumidores vindos de toda parte do Brasil, e em períodos festivos, o amplo estacionamento do centro comercial não suporta a massa de veículos que chega com ávidos compradores. As proximidades do estabelecimento ficam repletas de carros estacionados, muitas vezes em estacionamentos improvisados, como pode ser observado na imagem a seguir (Figura 2). No domingo (03/12/2017), o Moda Center registrou mais de 100 mil clientes, vindos das mais diversas regiões do país, de acordo com informação divulgada na página deles em uma rede social. Ao fundo da imagem está o Moda Center e seu estacionamento, enquanto no primeiro plano estão os estacionamentos improvisados.

Figura 2 - Fotografia aérea do Moda Center Santa Cruz e seu entorno.

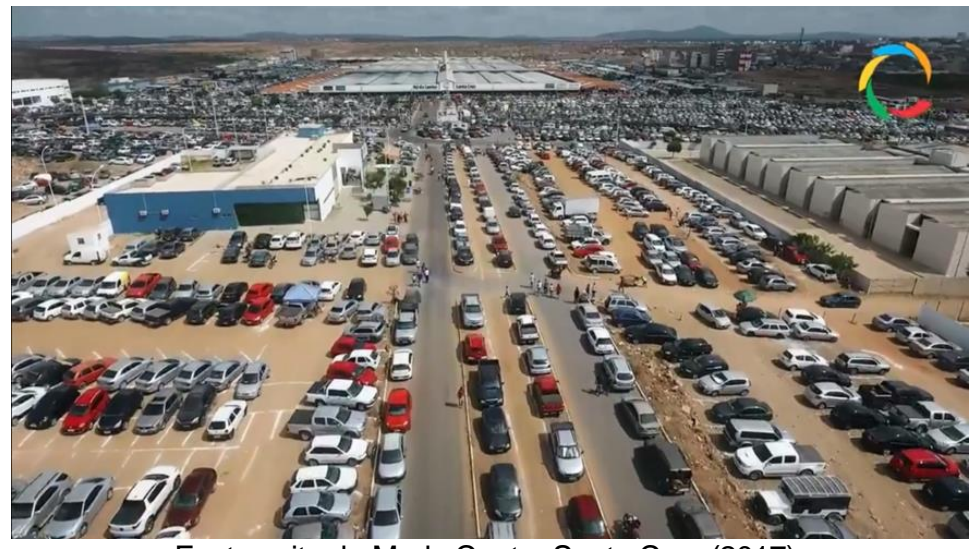

Fonte - site do Moda Center Santa Cruz (2017).

$\begin{array}{llllll}\text { Caminhos de Geografia } & \text { Uberlândia - MG } & \text { v. 21, n. 73 } & \text { Mar/2020 } & \text { p. 429-444 Página } 437\end{array}$ 
Figura 3 - Mapa de município de origem dos vendedores no Moda Center Santa Cruz.

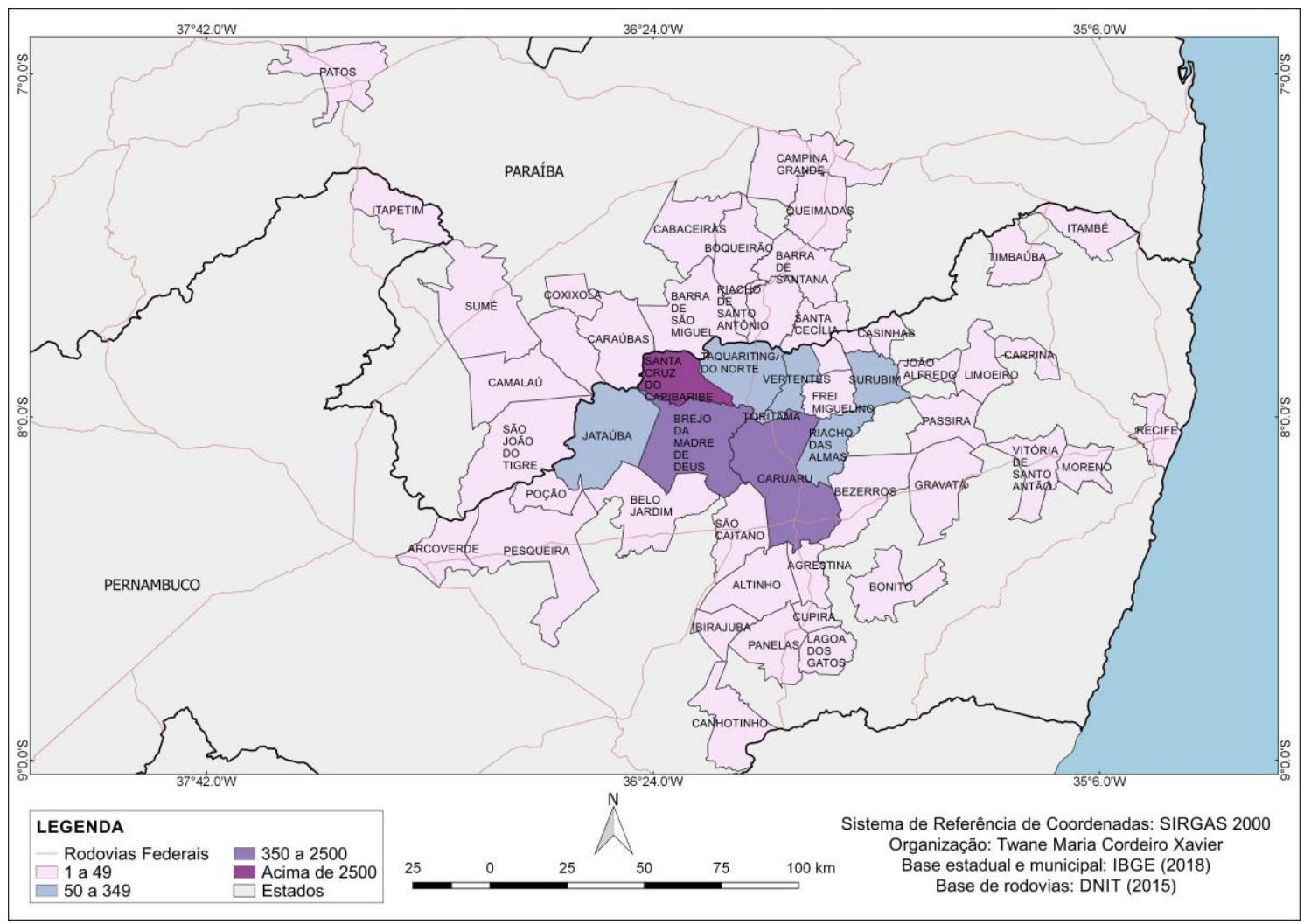

Fonte - elaborado com base em informação disponibilizada pela Prefeitura de Santa Cruz do Capibaribe. (2018).

Ao observar esse mapa, volta a ser visível o conjunto de cidades que se destaca, com um maior quantitativo de empreendedores originários da própria cidade de Santa Cruz do Capibaribe, mas ressaltando a importância do centro da moda para mais 8 municípios vizinhos: Brejo da Madre de Deus, Caruaru, Toritama, Riacho das Almas, Taquaritinga do Norte, Vertentes, Surubim e Jataúba, com valores acima de 350. Possivelmente, Caruaru e Toritama podem apresentar um número não tão alto quanto o de Santa Cruz, porque ambos os municípios também possuem seus centros comerciais e seus dias específicos de grandes feiras. O número exato relativo a cada um dos municípios não foi divulgado na publicação da Prefeitura de Santa Cruz do Capibaribe, por isso não foram mostrados aqui.

Para completar a identificação das cidades, e tendo em vista o foco sobre Santa Cruz do Capibaribe, também foi realizada uma observação mais detalhada sobre o deslocamento pendular por motivo de trabalho para o município. $O$ dado foi obtido utilizando o cruzamento de três variáveis disponibilizadas nos microdados do Censo Demográfico 2010, foram elas: V0660 - "Em que município e Unidade da Federação ou país estrangeiro trabalha"; V0661 - "Retorno diário do trabalho para o domicílio e a V0002 "Município de residência". Primeiramente foi realizado um filtro na variável V0660, no qual a categoria de resposta correspondesse a "Em outro município". Posteriormente foi realizado outro filtro na variável V0661, onde a categoria de resposta correspondesse a "sim". Por fim foi realizado o filtro na variável V0002, com a categoria de resposta igual ao código do município de Santa Cruz do Capibaribe, chegando aos valores.

De acordo com os dados a cidade de Santa Cruz do Capibaribe recebe 2577 trabalhadores pendulares diariamente, enquanto saem apenas 599. Em um município que possui população ocupada de cerca de 15 mil pessoas, esse quantitativo de pendulares é relativamente alto. Cabe ressaltar que quase metade desse número total de pendulares, é de trabalhadores vindos do distrito de São Domingos, pertencente ao município de Brejo da Madre de Deus, com um quantitativo de 1156 pendulares, correspondendo a $74,10 \%$ do total de população desse município que se desloca pendularmente para trabalho. Os municípios de Taquaritinga do Norte - PE e Caraúbas - PB também merecem destaque, pois possuem um percentual de $70,08 \%$ e $66,67 \%$ de sua população de pendulares para trabalho com deslocamento para Santa Cruz do Capibaribe. Para uma melhor visualização dos municípios que mais enviam trabalhadores 
pendulares para Santa Cruz do Capibaribe, associado à porcentagem que representa essa população em relação ao total de pendulares por município, os dados foram espacializados (Figura 4).

Figura 4 - Mapa de município de origem dos trabalhadores pendulares em Santa Cruz do Capibaribe (2010).

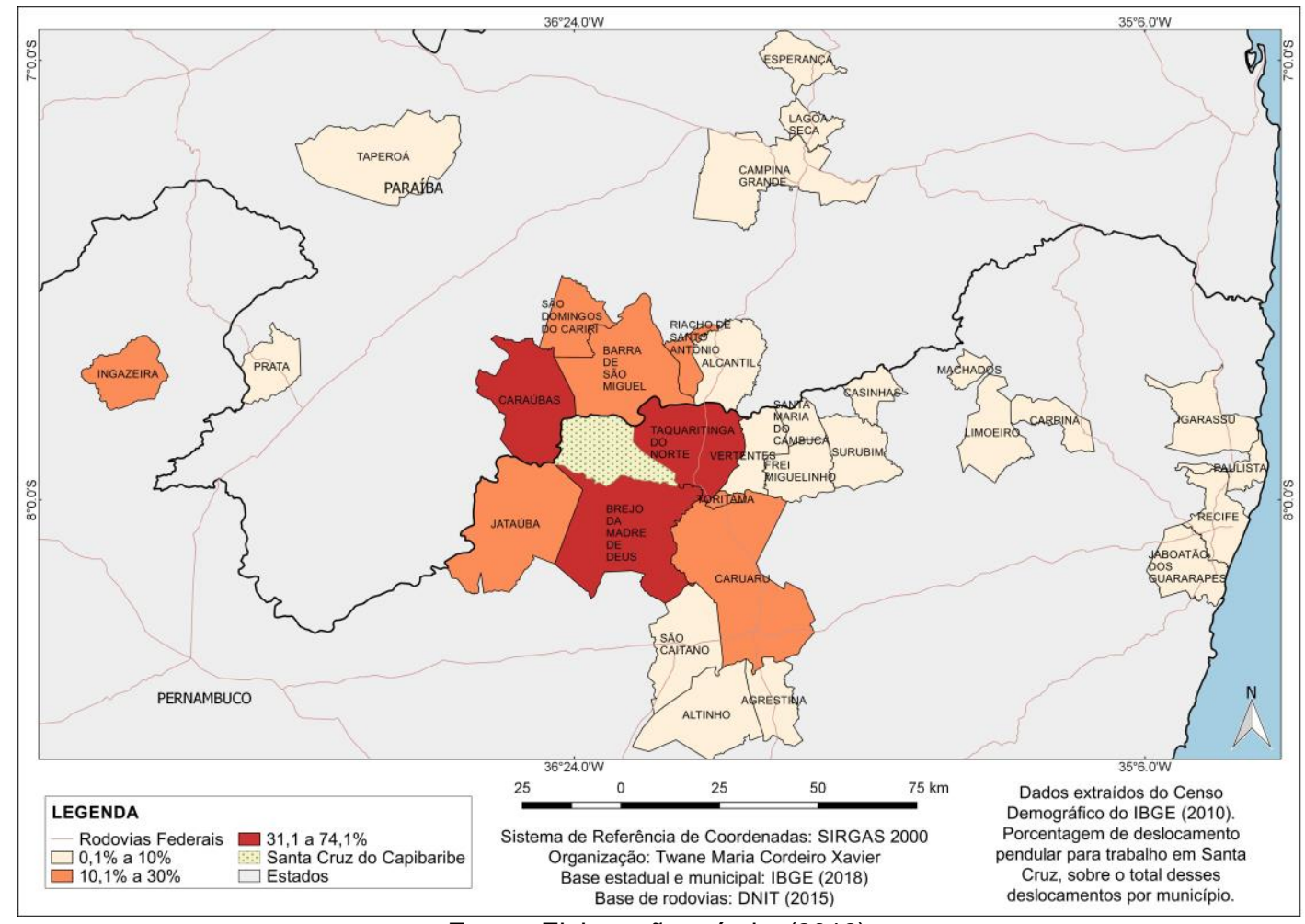

Fonte - Elaboração própria. (2018).

Com os mapas aqui expostos, ficaram claros os municípios que mais se destacam dentro do polo. Nesse último caso, evidencia-se a influência da cidade de Santa Cruz do Capibaribe enquanto importante destino para trabalho, o que ressalta a sua importância dentro do Polo de Confecções. No primeiro mapa, o mais importante em relação à produção de confecções, foi vista uma forte concentração dessa produção nos municípios do Agreste pernambucano, e a evidente formação de um agrupamento de cidades com especialização produtiva. Enquanto o mapa dos empreendedores do Moda Center mostra a importância desse centro de venda para uma grande quantidade de municípios dos dois estados. A concentração espacial devido à especialização produtiva é notória na região, mas pode ser um pouco equivocada uma delimitação específica de quais são os municípios que fazem parte do Polo e de quais não fazem, por isso optou-se por não indicar essa demarcação de forma precisa neste momento. Existe uma relação de influência forte na região, principalmente por parte das três principais cidades, que será detalhada no item a seguir. Assim, há um conjunto de cidades que acabam dependendo da dinâmica econômica provocada pelas atividades de confecção.

\section{IDENTIFICAÇÃO DE UMA ÁREA CORE E UMA PERIFÉRICA NO POLO E SUAS RELAÇÕES DE INFLUÊNCIA}

Com sua origem na cidade de Santa Cruz do Capibaribe, expandindo em poucos anos para Toritama e Caruaru, o Polo de Confecções do Agreste de Pernambuco, conta com um conjunto de cidades com micro e pequenos empreendedores que também fizeram da confecção uma importante atividade econômica para seu município. A produção formal é concentrada na região do Agreste, como visto no item anterior, mas não apenas essa produção é responsável pelo dinamismo que atinge os municípios. A 
comercialização e os serviços são fatores que influenciam ainda mais nessa dinâmica, principalmente quando se procura entender qual a área core e a periférica do Polo.

A cidade de Caruaru, merece destaque por ter sua origem como uma das cidades Bocas de Sertão, denominação dada inicialmente para "designar vilas que surgiram longe da orla litorânea a partir do século XVII" (MAIA, 2017, p.27). Além disso, as cidades que se formavam através do caminho de passagem do gado, de fazendas ou pequenos centros para encontros comerciais através das pequenas feiras, também poderiam ser denominadas dessa forma (AZEVEDO, 1970 apud MAIA, 2017). Com a chegada da ferrovia a Caruaru em 1895, a até então vila, começou a expandir, ganhou o título de cidade e passou a exercer ainda mais um papel de centralidade na região do agreste pernambucano, por meio da intermediação de produtos entre o litoral e o sertão (ALMEIDA, 2015). Aos poucos, a cidade cresceu, desenvolvendo indústrias e serviços, e em meados do século XX se reafirmou como principal cidade do interior do estado de Pernambuco. A tradicional feira já era bastante conhecida, e a partir da década de 1970, os empreendedores da cidade começaram a incorporar as atividades de confecções, seguindo Santa Cruz do Capibaribe.

Atualmente, Caruaru, continua com seu papel de destaque ao se tornar uma das principais cidades da aglomeração, bem como cidade média, possuindo uma oferta de serviços bem superior à das demais cidades. Dessa forma, apesar das três principais cidades possuírem dinâmicas muito próximas no que se refere à produção de confecções, as outras duas principais e as demais cidades do polo ainda dependem da maior diversidade de que dispõe Caruaru, resultando em relações de influência provocadas por sua maior pluralidade de funções. Nela é encontrada grande oferta de escolas de cursos superiores privados, além das unidades públicas do Instituto Federal de Pernambuco e da Universidade Federal de Pernambuco, e unidades do sistema S, como o Serviço Nacional de Aprendizagem Comercial (SENAC) e (SENAI), sendo principal destino buscado pelos estudantes da região. Conta também com uma grande quantidade de agências bancárias, de hospitais (privados e públicos), de rede hoteleira, e demais serviços essenciais, tais como escolas, creches, rodoviárias e um aeroporto.

Santa Cruz do Capibaribe, que teve sua economia transformada desde o início do processo de produção de confecções, concentra o maior número de unidades produtivas formais e informais, estimada pelo SEBRAE (2013) em 7.169 unidades. Enquanto Caruaru aparece com 4.530 e Toritama com 2.818 (SEBRAE, 2013), seguidas por Brejo da Madre de Deus e Taquaritinga do Norte, com 1.396 e 1.185 unidades produtivas, respectivamente. Esses valores diferem do apresentado no mapa da RAIS, porque são baseados em estimativas que contaram também com os estabelecimentos informais, mas não se distanciam do núcleo com maior porcentagem de indústria de confecções em relação ao total de indústrias da transformação mostrado no mapa supracitado. Santa Cruz do Capibaribe, então, desponta como principal cidade do ponto de vista do quantitativo de unidades produtivas bem como, dentre as três, a que possui o maior centro comercial, influenciando também na atratividade de compradores que vêm de todo o país.

A cidade de Toritama, mesmo como menor cidade em extensão territorial e menor quantitativo populacional quando comparada às outras duas, aparece como uma gigante produtora de jeans, a principal da região. Ela entrou no ramo das confecções por volta das décadas de 1970 e 1980, como uma saída econômica devido ao aumento do preço do couro, pois os artesãos produziam calçados com essa matéria-prima, que já havia sido um escape durante o período de crise no "sistema gado-policultura" que ocorrera por volta dos anos 1960 (VASCONCELOS, 2012, p.58). Na cidade são encontradas muitas lavanderias, algumas que atuam na informalidade e outras formalmente, mas diferente da produção em Santa Cruz do Capibaribe e Caruaru, que não possuem foco no jeans, muitas dessas empresas acabam poluindo o Rio Capibaribe com os rejeitos dos procedimentos de lavagem, descoloração e tingimento, assunto que já foi e continua sendo abordado em muitos trabalhos acadêmicos relacionados ao município e também pela mídia, principalmente quando há alguma denúncia. Algumas empresas possuem um sistema de tratamento da água antes dela ser despejada no rio, mas nem todas elas realmente o fazem ou, mesmo as que possuem o sistema de tratamento, ainda assim, despejam o líquido irregularmente no rio.

Os três municípios supracitados são, portanto, o núcleo do Polo de Confecções, e são eles que exercem maior influência sobre os demais, tanto no que tange ao mercado de trabalho como também nos serviços. Mas apesar de não ser apresentada aqui uma definição específica de quais são os municípios que compõem esse Polo, a partir dos três mapas elaborados para ajudar na compreensão da formação da região, foi construído um mapa com a região de abrangência dessas atividades de confecções nos dois Estados (Figura 5).

Caminhos de Geografia Uberlândia - MG $\quad$ v. 21, n. 73 $\quad$ Mar/2020 $\quad$ p. 429-444 Página 440


Figura 5 - Mapa da abrangência da região produtora do Polo de Confecções do Agreste de Pernambuco.

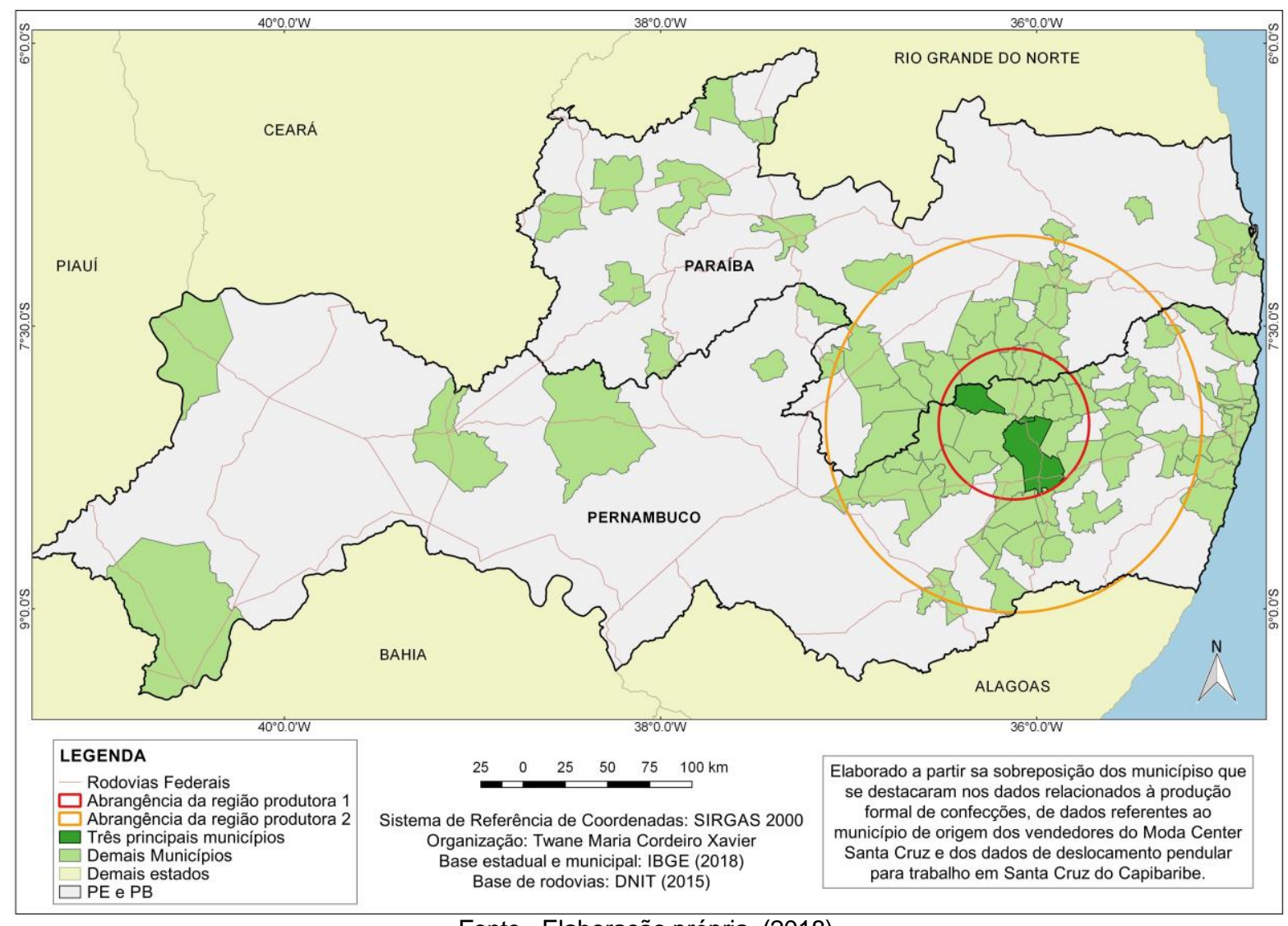

Fonte - Elaboração própria. (2018).

A abrangência da região produtora 1 (raio de $45 \mathrm{~km}$ ), conta com os três principais municípios do Polo e os que mais se destacaram nos mapas anteriores, com ênfase principal nos municípios que obtiveram maior concentração de unidades produtivas voltadas para a confecção, ressaltando uma especialização na região. As cidades de Brejo da Madre de Deus, Jataúba, Taquaritinga do Norte, Vertentes e Riacho das Almas, além demonstrarem alta produção, foram algumas das que apresentaram maior deslocamento pendular para trabalho e quantitativo de empreendedores que atuam no Moda Center Santa Cruz. Por isso a área foi interpretada como a mais especializada e voltada para às atividades do Polo de Confecções. O centro comercial de Santa Cruz do Capibaribe, com sua atratividade de comerciantes e compradores, acaba se tornando um indicador também dessa concentração e influência da área core do Polo.

A abrangência da região produtora 2 (raio de 110km), por sua vez, alcança os demais municípios que não possuem atuação tão intensa em relação à confecção, mas que estão interligados também ao polo, devido à produção e à comercialização no Moda Center, mesmo que com menor participação. $O$ alto número de pequenas cidades dentro dessa região mais periférica, ressalta a necessidade de uma melhor compreensão sobre até que ponto suas estruturas socioeconômicas são influenciadas pelo Polo de Confecções. Essa compreensão é um desafio, que envolve um trabalho mais detalhado e minucioso sobre a região.

A centralidade da região pode também ser vista através do saldo do deslocamento pendular para trabalho em relação a seis municípios (Quadro 5). Para esta comparação na tabela, foram selecionadas as três principais cidades do Polo e os três municípios que tiveram maior percentual de deslocamento em direção a Santa Cruz do Capibaribe. 
Quadro 5 - Comparação do quantitativo de deslocamento pendular para trabalho.

\begin{tabular}{|l|ccc|}
\hline \multicolumn{4}{|c|}{ DESLOCAMENTO PENDULAR PARA TRABALHO - 2010 } \\
\hline \multicolumn{1}{|c|}{ MUNICÍPIOS } & Ingressos & Egressos & Saldo \\
\hline Santa Cruz do Capibaribe & 2475 & 599 & 1876 \\
Toritama & 2879 & 247 & 2632 \\
Caruaru & 8535 & 2384 & 6151 \\
Brejo da Madre de Deus & 296 & 1560 & -1264 \\
Taquaritinga do Norte & 286 & 762 & -476 \\
Jataúba & 78 & 203 & -125 \\
\hline
\end{tabular}

Fonte: IBGE (2016).

Pode se observar um alto quantitativo de trabalhadores que se deslocam para as três principais cidades do Polo, nas quais o valor de ingressos é bem maior do que os que saem (egressos) para outras cidades, enquanto nas outras três o saldo é negativo. Isso ressalta a capacidade de atratividade das principais cidades em relação à mão-de-obra.

De fato, existe uma área onde a especialização produtiva volta-se para o mercado de confecções, incluindo não apenas municípios de Pernambuco, como também da Paraíba, mesmo que dentre os localizados nesse último, em alguns casos, exista uma produção independente e de segmento mais específico. Como as redes de dormir em São Bento - PB e os panos de prato, de chão e toalhas em Itaporanga - PB. Enquanto em Pernambuco, há um segmento diferenciado em Pesqueira e Poção, com a renda Renascença, produto artesanal de alto valor no mercado, inclusive internacional.

\section{CONSIDERAÇÕES FINAIS}

As mudanças que a realização mais intensa de determinada atividade econômica provoca em uma cidade ou região, podem ir além das expectativas dos primeiros agentes produtores dessa atividade na localidade. A fabricação e a venda podem começar de maneira tímida, destinada apenas ao público local ou de sua hinterlândia, mas aos poucos ir ocupando cada vez mais espaço no mercado, o que transforma a realidade dos empreendedores, devido ao aumento da concorrência, e provoca especialização produtiva com a busca pelo aumento dos lucros. Isso pôde ser visto na área de estudo aqui evidenciada.

Neste trabalho, foi possível observar a constituição de uma aglomeração produtiva voltada para as confecções e identificar quais cidades participam desse conjunto de maneira mais e menos intensa, por meio da área de abrangência da região produtora, apresentada no mapa cujos dados indicaram a duas áreas principais. Ao observar que as atividades de confecção na região alcançam, majoritariamente, as micro e pequenos produtores, além de grande parcela das indústrias da transformação serem voltadas para a confecção, torna-se evidente a formação de uma região com especialização produtiva. $E$ as demais características dessa região que, em 2016, possuía 2 mil empresas formais, possui mais de 100 mil pessoas ocupadas tanto na produção quanto na venda de vestuário, alta incidência de trabalho familiar e proximidade territorial entre os municípios, que possibilita maior deslocamento pendular para trabalho, ressaltam a sua estrutura enquanto aglomeração produtiva.

Apesar de não existir delimitação oficial quanto às cidades que compõem o Polo de Confecções do Agreste de Pernambuco, o percentual de participação da confecção sobre o total das indústrias nas cidades, deixa claro que existe maior concentração das atividades e o deslocamento para venda e trabalho mostra quais municípios recebem maiores fluxos de pessoas relacionadas ao ramo. Se sobressaíram as três principais cidades do Polo, Santa Cruz do Capibaribe, Toritama e Caruaru, que foram as únicas a apresentarem saldo positivo quando contabilizado os trabalhadores ingressos e egressos que se deslocam pendularmente. Isso ressaltou a área core da aglomeração produtiva, mas não deixando de observar que Caruaru exerce essa atratividade também por outros motivos, dos quais o principal corresponde a oferta de maior diversidade de trabalho por ser ela uma cidade com características de capital regional. 
Alguns municípios se destacaram como participantes dessa aglomeração, inclusive do estado da Paraíba, cujos dados mostraram consideráveis quantidades de unidades produtivas de confecção, de deslocamento para trabalho e de município de origem dos comerciantes do Moda Center Santa Cruz. Além dos três principais, ressaltaram-se os municípios de Brejo da Madre de Deus, Taquaritinga do Norte, Jataúba, Riacho das Almas, Vertentes, São Caitano, Santa Maria do Cambucá, Surubim e Cupira, em Pernambuco, e Caraúbas, São Domingos do Cariri, Barra de São Miguel e Riacho de Santo Antônio, na Paraíba. Apresentando, assim, um conjunto de cidades sobre as quais as atividades de confecções exercem influência no âmbito do mercado produtivo e de trabalho. Os municípios de São Bento e Itaporanga, na Paraíba, que aparecem no mapa das indústrias de confecção, juntamente com os municípios que os circundam e também apareceram nesse mapa, não estão nos outros dois mapas (o de Empreendedores no Moda Center e o de Deslocamento Pendular), possivelmente por consistir na formação de uma outra aglomeração produtiva, não vinculada ao Polo de Confecções aqui estudado, o que merece ser investigado em pesquisas futuras. Mas é importante notar que as atividades de confecção assumem características espaciais diversas na base cartográfica que serviu para identificar o aglomerado produtivo agrestino, centrado em Santa Cruz do Capibaribe, Toritama e Caruaru, e que estudos com maior aprofundamento são de extrema importância para melhor compreensão das dinâmicas socioespaciais incidentes na região.

\section{AGRADECIMENTOS}

Agradeço a Coordenação de Aperfeiçoamento de Pessoal e Nível Superior (CAPES), pela concessão de bolsa de mestrado durante todo os dois anos de curso no Programa de Pós-Graduação em Geografia da Universidade Federal de Pernambuco.

\section{REFERÊNCIAS}

ALMEIDA, A. P. A. O papel da cidade média de caruaru na estruturação da rede urbana pernambucana. Anais do III Simpósio Internacional Cidades Médias, UFRJ/ReCiMe, abril de 2015. p.103120.

CATELAN, M. J. Heterarquia urbana: interações espaciais interescalares e cidades médias. São Paulo: Cultura Acadêmica, 2013.

COSTA, J. M. Arranjos Produtivos Locais, políticas públicas e desenvolvimento regional. Brasília: Mais Gráfica, 2010.

CROCCO, M. A.; GALINARI, R.; SANTOS, F.; LEMOS, M. B.; SSIMÕES, R. Metodologia de identificação de aglomerações produtivas locais. Nova Economia, Belo Horizonte, v. 16, n. 2, p. 211241, 2006. https://doi.org/10.1590/S0103-63512006000200001

DIEESE. Diagnóstico do Setor Têxtil e de Confecções de Caruaru e Região. Relatório final. Recife: Governo de Pernambuco, 2010.

FRESCA, T. M. Centros locais e pequenas cidades: diferenças necessárias. Mercator, Fortaleza, v. 9, n. 20, p. 75-81, 2010. https://doi.org/10.4215/RM2010.0920.0005

IBGE. Censo Demográfico. Rio de Janeiro, 2010

LIRA, S. M. Os aglomerados de micro e pequenas indústrias de confecções do agreste/PE: um espaço construído na luta pela sobrevivência. Revista de Geografia da UFPE, Recife, n. 23, v. 1, p. 98-114, 2006.

O "desenvolvimento" do aglomerado de micro e pequenas indústrias de confecções do Agreste/PE: as suas inter-relações socioespaciais. 2009. 2014f. Tese (doutorado) - Programa de Pósgraduação em Geografia, Centro de Filosofia e Ciências Humanas, Universidade Federal de Pernambuco. Recife, 2009.

MAIA, D. S. Cidades Bocas de Sertão: sobre a origem e constituição no Núcleo Primaz e os primeiros indícios do processo de urbanização. In: MAIA, D. S.; SILVA, W. R.; WHITACKER, A. M. Centro e centralidade em cidades médias. 1. ed. São Paulo: Cultura Acadêmica, 2017. https://doi.org/10.4000/terrabrasilis.2160

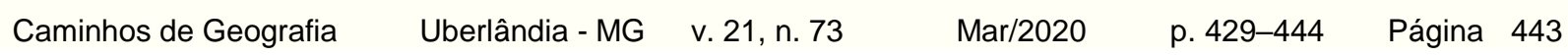


PEREIRA NETO, E. V. Qualificação e informalidade: os modos de atuação do SENAl no Polo de Confecções de Pernambuco. Recife: FUNDAJ, 2013.

PICCININI, F. J.; FINAMORE, E. B. M. C.; OLIVEIRA, G. Identificação e mapeamento de Aglomerações Produtivas no Rio Grande do Sul: Um enfoque na região da produção. Caderno de Economia, Chapecó, v 15, n 28, p. 18-31, 2011.

RODRIGUES, M. A.; MONTEIRO, W. F.; CAMPOS, A. C.; PARRÉ, J. L. Identificação e análise espacial das aglomerações produtivas do setor de confecções na região Sul. Economia Aplicada, São Paulo, v. 16, n. 2, p. 311-338, 2012.

SANTOS, M. Tendências da Urbanização Brasileira. In. CARLOS, A. F. A. (Org). Os Caminhos da Reflexão sobre a Cidade e o Urbano. São Paulo: EDUSP, 1994.

SANTOS, G. A. G.; DINIZ, E. J.; BARBOSA, E. K. Aglomerações, arranjos produtivos locais e vantagens competitivas locacionais. Revista do BNDES, Rio de Janeiro, v. 11, n. 22, p. 151-179, 2004.

SEBRAE. Estudo econômico do arranjo produtivo local de confecções do Agreste. Relatório final Serviço de Apoio às Micro e Pequenas Empresas do Estado de Pernambuco. SEBRAE, Pernambuco, 2013. 151p.

SIMONETTI E. R. S.; KAMIMURA, Q. P. As Políticas Públicas Direcionadas ao Desenvolvimento de Arranjos Produtivos Locais. In: OLIVEIRA, C. W. A. et. al. (Org). Arranjos produtivos locais e desenvolvimento. Rio de Janeiro: Ipea, 2017.

VASCONCELOS, V. M. Migração e pendularidade: as consequências de atração de população para o município de Toritama - PE. 2012. 185f. Dissertação (Mestrado) - Programa de Pós-graduação em Geografia, Centro de Filosofia e Geociências, Universidade Federal de Pernambuco. Recife, 2012.

VÉRAS DE OLIVEIRA, R. O Polo de Confecções do Agreste Pernambucano: ensaiando uma perspectiva de abordagem. In: ARAÚJO, A; OLIVEIRA, R. (Org.). Formas de trabalho no capitalismo atual. São Paulo: Annablume, 2011.

XAVIER, M. G. P. O processo de produção do espaço urbano em economia retardatária: a aglomeração produtiva de Santa Cruz do Capibaribe (1960-2000). 2006. 254f. Tese (Doutorado) - Pósgraduação em Desenvolvimento Urbano, Centro de Artes e Comunicação, Universidade Federal de Pernambuco. Recife, 2006.

Recebido em: 02/07/2019

Aceito para publicação em: 06/08/2019 